\title{
PHENOTYPIC CONSOLIDATION DAUGHTERS OF BULL-SIRES ESTIMATED BY THE METHOD OF LINEAR CLASSIFICATION
}

\author{
Khmelnychyi Leontiy Mykhailovych \\ Doctor of Agricultural Sciences, Professor \\ Sumy National Agrarian University \\ ORCID: 0000-0001-5175-1291 \\ E-mail: khmelnychy@ukr.net \\ Khmelnychyi Serhii Leontievych \\ $\mathrm{PhD}$ in agricultural sciences \\ Sumy National Agrarian University \\ ORCID: 0000-0003-2352-3317 \\ E-mail: serhiokh@ukr.net \\ Bardash Dmitryi Alexandrovych \\ graduate student specialty 204-TVPPT \\ Sumy National Agrarian University \\ ORCID: 0000-0002-9368-2324 \\ E-mail: d.bardash@ukr.net
}

The aim of our research was to determine the degree of phenotypic consolidation coefficients of bull-sires daughters in the Sumy intra-breed type of Ukrainian Black-and-White dairy breed, estimated by linear traits that characterize the conformation type of cows. The experimental base of research was information on the linear classification of first-calf cows of Sumy intra-breed type of Ukrainian Black-and-White dairy breed in the PE "Burynske" breeding farm in Pidlisnivskyi department of Sumy district. The estimation of the first-calf cows by type was carried out using the method of linear classification by two systems: 9-point, with a linear description of 18 conformation traits and 100-point including four complexes of breeding traits that characterize: dairy type, body, limbs and udder. The coefficients of phenotypic consolidation (K1 and K2) cows of selection groups for linear traits of the conformation were determined according to formulas proposed by Yu. P. Polupan (2005). The level of phenotypic consolidation daughters of bull-sires estimated by group conformation traits indicated that regardless of the origin, phenotypic consolidation coefficients by overall type assessment had a positive value with a wide variability of coefficient $K_{1}$ from 0.056 to 0.512 and coefficient $K_{2}$ - from 0.065 to 0.505 . Among all estimated by phenotypic consolidation bulls, less consolidated by group linear traits were found sires of Ukrainian Black-and-White dairy breed - Motuzok and Front. Among sires of Holstein breed the best by group traits and overall assessment of the type were: $V$. Delight $\left(K_{1}=0.242-0.334 ; K_{2}=0.247-0.349\right) ; D$. Capris $\left(K_{1}=0.085-0.341 ; K_{2}=\right.$ 0.089-0.348) and Hayes $\left(K_{1}=0.071-0.375 ; K_{2}=0.082-0.370\right)$. From the sires of Ukrainian Black-and-White dairy breed the Iceberg was the best $\left(K_{1}=0.059-0.478 ; K_{2}=0.047-0.472\right)$. Magnitude of the degree phenotypic consolidation of descriptive traits of linear estimation daughters of bull-sires, regardless of origin, differed significantly by higher variability in comparison with group traits. Coefficients of phenotypic consolidation calculated by the formula $K_{1}$, varied according to the bull-sires assessment from -0.434 (teats length of Iceberg daughters) to 0.504 (rump angle of Milliam daughters). The higher variability of phenotypic consolidation coefficients was revealed according to the formula $K_{2}$, whose level varied from -0.571 (udder depth of Lyubimy's daughters) to 0.546 (angularity of Milliam daughters). By the coefficients of phenotypic consolidation of descriptive traits $K_{1}$ and $K_{2}$, there wasn't found no one bull-sire only with positive values. The most consolidated for overwhelming majority of descriptive traits were the bulls-sires of Holstein breed - Lauer, Toprate and Milliam. The highest consolidation of descriptive traits had all daughters of bulls by angularity with the highest number of positive values of coefficients. The presence of a genetic influence of bull-sires on the degree of phenotypic consolidation of the majority of linear traits of daughters with a significant advantage of Holstein producers was established.

Key words: Ukrainian Black-and-White dairy breed, conformation type, phenotypic consolidation, bull-sires.

DOl: https://doi.org/10.32845/bsnau.lvst.2020.1.4

Important characteristics and mandatory conditions for further testing and genetic progress breeds and their breeding structural units was their genetic and phenotypic specificity and a certain degree of consolidation [9]. Achievement of the desired level of phenotypic consolidation of intra-breed breeding formations required, first of all, the presence of genetically grounded and, at the same time, simple and available in determining the criterion for its assessment, proposed by Yu. P. Polupan [10], phenotypic consolidation coefficients. They depended on an estimate of the relative decrease in variability within the breeding group.

A number of scientists reported that the practical use of

coefficients of phenotypic consolidation made it possible to objectively differentiate various breeding groups of animals according to traits characterizing reproductive ability [7], productivity [3], lifetime use [2], constitutional types [12] and animal conformation [14, 15].

Considering that in conditions of large-scale breeding, the role of bull-sires was of key importance, due to their influence on the genetic improvement of the population at the level of $85-95 \%$ [1], determination the level of phenotypic consolidation of breeding groups of middle and lower levels of the intra-breed structural system hierarchy (half-sibs group) should become the subject of constant monitoring during their 
genesis and be taken into account to objectively determine the ways of further selection [9]. About the effectiveness of influence of bull-sires on the development of the conformation traits of their daughters, estimated by the method of linear classification, was reported by many studies $[4,8,13]$.

In this regard, the aim of our research was to determine the degree of phenotypic consolidation coefficients daughters of bull-sires Sumy intra-breed type of the Ukrainian Black-andWhite dairy breed, estimated by linear traits, characterizing the conformation type of animals.

Materials and research methods. The experimental base of research was information on the linear classification of first-calf cows of Sumy intra-breed type of Ukrainian Black-andWhite dairy breed in the PE "Burynske" breeding farm in Pidlisnivskyi department of Sumy district. out using the method of linear classification [6] according to the ICAR recommendations [11] according to two systems: 9-point with a linear description of 18 conformation traits and 100-point - taking into account four sets of selection traits that characterize: dairy type, body, limbs and udder.

The coefficients of phenotypic consolidation ( $\mathrm{K}_{1}$ and $\mathrm{K}_{2}$ ) of selection groups of animals based on linear traits of the conformation were determined according to formulas proposed by Yu. P. Polupan [9]:
The assessment of first-calf cows by type was carried

$$
K_{1}=1-\frac{\sigma_{2}}{\sigma_{3}} ; \quad K_{2}=1-\frac{C v_{2}}{C v_{3}}
$$

where: $\sigma_{2}$ and $C v_{2}-$ mean deviation and coefficient of variability estimated group of animals by a specific trait

$\sigma_{3}$ i $C_{3}$ - the same indicators of general population

Research materials were processed on a computer using software according to the formulas described by E. K. Merkurieva [5].

Research results. The level of phenotypic consolidation daughters of bull-sires, estimated by group traits of the conformation, testified that regardless of the origin, coefficients of phenotypic consolidation according to the overall assessment of type had a positive value with wide variability in terms of coefficient $\mathrm{K}_{1}$ from 0.056 to 0.512 and according to the coefficient $\mathrm{K}_{2}$ from 0.065 to 0.505 . tab. 1. Among all bull-sires evaluated by phenotypic consolidation, producers of Ukrainian Black-and-White dairy breed - Motuzok and Front turned out to be less consolidated by group linear traits. Among bull-sires of Holstein breed the best by group traits and overall assessment of the type were: V. Delight $\left(\mathrm{K}_{1}=0.242-0.334 ; \mathrm{K}_{2}=0.247-0.349\right)$; $\mathrm{D}$. Capris $\left(K_{1}=0.085-0.341 ; K_{2}=0.089-0.348\right)$ and Hayes $\left(K_{1}=0.071-\right.$ $0.375 ; K_{2}=0.082-0.370$ ). From bull-sires of Ukrainian Black-andWhite dairy breed the Iceberg was the best $\left(K_{1}=0.059-0.478 ; K_{2}\right.$ $=0.047-0.472$ ).

Table 1

Phenotypic consolidation daughters of bull-sires by group traits of the conformation

\begin{tabular}{|c|c|c|c|c|c|c|c|c|c|c|}
\hline \multirow{4}{*}{ Bull-sire } & \multicolumn{8}{|c|}{ Set of traits: } & \multirow{2}{*}{\multicolumn{2}{|c|}{ Overall assessment }} \\
\hline & \multicolumn{2}{|c|}{ dairy type } & \multicolumn{2}{|c|}{ body } & \multicolumn{2}{|c|}{ limbs } & \multicolumn{2}{|c|}{ udder } & & \\
\hline & \multicolumn{10}{|c|}{ coefficients of phenotypic consolidation } \\
\hline & $\mathrm{K}_{1}$ & $\mathrm{~K}_{2}$ & $\mathrm{~K}_{1}$ & $\mathrm{~K}_{2}$ & $\mathrm{~K}_{1}$ & $\mathrm{~K}_{2}$ & $\mathrm{~K}_{1}$ & $\mathrm{~K}_{2}$ & $\mathrm{~K}_{1}$ & $\mathrm{~K}_{2}$ \\
\hline Iceberg $(n=30)$ & 0,283 & 0,281 & 0,119 & 0,108 & 0,059 & 0,047 & 0,210 & 0,204 & 0,478 & 0,472 \\
\hline V. Delight $(n=37)$ & 0,322 & 0,328 & 0,242 & 0,247 & 0,261 & 0,268 & 0,305 & 0,309 & 0,347 & 0,349 \\
\hline D. Capris $(n=41)$ & 0,341 & 0,348 & 0,085 & 0,089 & 0,195 & 0,202 & 0,250 & 0,256 & 0,235 & 0,248 \\
\hline Laurer $(n=21)$ & 0,299 & 0,308 & 0,039 & 0,041 & 0,154 & 0,157 & $-0,010$ & 0,005 & 0,343 & 0,344 \\
\hline Hayes $(n=22)$ & 0,071 & 0,082 & 0,228 & 0,234 & 0,375 & 0,370 & 0,216 & 0,225 & 0,194 & 0,201 \\
\hline Lyubimyy $(n=30)$ & $-0,017$ & $-0,029$ & 0,201 & 0,193 & 0,343 & 0,339 & 0,183 & 0,173 & 0,372 & 0,364 \\
\hline Toprate $(n=39)$ & 0,164 & 0,173 & 0,031 & 0,036 & 0,077 & 0,088 & 0,150 & 0,158 & 0,213 & 0,219 \\
\hline Modnyy (n=25) & 0,206 & 0,201 & 0,007 & 0,000 & $-0,301$ & $-0,322$ & 0,288 & 0,280 & 0,512 & 0,505 \\
\hline Motuzok $(n=21)$ & $-0,242$ & $-0,258$ & 0,223 & 0,212 & $-0,026$ & $-0,044$ & 0,117 & 0,106 & 0,174 & 0,162 \\
\hline Milliam $(n=28)$ & 0,178 & 0,193 & 0,128 & 0,129 & 0,259 & 0,269 & $-0,047$ & $-0,035$ & 0,056 & 0,065 \\
\hline Front $(n=30)$ & 0,060 & 0,056 & 0,040 & 0,030 & 0,011 & 0,000 & 0,175 & 0,163 & 0,331 & 0,322 \\
\hline
\end{tabular}

The magnitude of phenotypic consolidation degree of the descriptive traits of linear assessment of bull-sires daughters, regardless of the origin, differed by significantly higher variability in comparison with group traits, tab. 2 and 3.

The coefficients of phenotypic consolidation, calculated using the K1 formula, varied according to the assessment of all bull-sires from -0.434 (teats length of Iceberg daughters) to 0.504 (rump angle of Milliam daughters). An even higher variability in the coefficients of phenotypic consolidation was found according to the $K_{2}$ formula, the level of which varied from
-0.571 (udder depth of Lyubimyy daughters) to 0.546 (angularity of Milliam daughters).

According to the coefficients of phenotypic consolidation of descriptive traits $\mathrm{K} 1$ and $\mathrm{K} 2$, there wasn't revealed a single sire only with positive values. The most consolidated for overwhelming majority of descriptive traits were bull-sires of Holstein breed - Lauer, Toprate and Milliam.

The highest consolidation among descriptive traits had daughters of all bull-sires on angularity with the largest number of positive coefficient values. 
Table 2

Coefficients of phenotypic consolidation $\left(K_{1}\right)$ of bull-sires daughters by descriptive traits of the conformation

\begin{tabular}{|c|c|c|c|c|c|c|c|c|c|c|c|c|}
\hline \multicolumn{2}{|c|}{$\begin{array}{l}\text { Descriptive trait of the } \\
\text { conformation: }\end{array}$} & $\begin{array}{c}\text { Iceberg } \\
(30)\end{array}$ & $\begin{array}{l}\text { V. Delight } \\
(n=37)\end{array}$ & $\begin{array}{l}\text { D. Capris } \\
(n=41)\end{array}$ & $\begin{array}{l}\text { Laurer } \\
(\mathrm{n}=21)\end{array}$ & $\begin{array}{l}\text { Hayes } \\
(\mathrm{n}=22)\end{array}$ & $\begin{array}{l}\text { Lyubimyy } \\
(\mathrm{n}=30)\end{array}$ & $\begin{array}{l}\text { Toprate } \\
(\mathrm{n}=39)\end{array}$ & $\begin{array}{l}\text { Modnyy } \\
(\mathrm{n}=25)\end{array}$ & $\begin{array}{c}\text { Motuzok } \\
(\mathrm{n}=21)\end{array}$ & $\begin{array}{l}\text { Milliam } \\
(\mathrm{n}=28)\end{array}$ & $\begin{array}{l}\text { Front } \\
(\mathrm{n}=30)\end{array}$ \\
\hline \multicolumn{2}{|c|}{ height at sacrum } & $-0,012$ & $-0,012$ & 0,124 & 0,042 & 0,098 & 0,173 & 0,176 & $-0,096$ & 0,177 & $-0,035$ & 0,251 \\
\hline \multicolumn{2}{|c|}{ chest width } & 0,046 & 0,046 & $-0,150$ & 0,432 & 0,141 & $-0,063$ & $-0,046$ & $-0,040$ & 0,316 & 0,254 & $-0,393$ \\
\hline \multicolumn{2}{|l|}{ body depth } & $-0,011$ & $-0,011$ & 0,260 & 0,070 & $-0,058$ & $-0,054$ & 0,281 & 0,335 & 0,065 & 0,222 & 0,017 \\
\hline \multicolumn{2}{|l|}{ angularity } & $-0,019$ & $-0,019$ & 0,449 & 0,402 & $-0,285$ & 0,389 & 0,395 & 0,292 & 0,013 & 0,470 & $-0,125$ \\
\hline \multicolumn{2}{|l|}{ rump angle } & $-0,354$ & $-0,354$ & $-0,076$ & 0,252 & 0,275 & $-0,163$ & 0,273 & $-0,015$ & 0,044 & 0,504 & $-0,145$ \\
\hline \multicolumn{2}{|l|}{ rear width } & 0,010 & 0,010 & 0,227 & 0,265 & 0,012 & $-0,003$ & 0,186 & $-0,092$ & $-0,071$ & 0,195 & 0,254 \\
\hline \multicolumn{2}{|c|}{ angle of pelvic limbs } & $-0,203$ & $-0,203$ & 0,110 & 0,355 & 0,109 & 0,382 & 0,022 & $-0,313$ & $-0,261$ & 0,355 & $-0,253$ \\
\hline \multicolumn{2}{|c|}{ pelvic limbs posture } & $-0,056$ & $-0,056$ & 0,101 & 0,190 & 0,188 & 0,021 & 0,166 & 0,205 & $-0,065$ & $-0,070$ & 0,238 \\
\hline \multicolumn{2}{|c|}{ hoof angle } & $-0,035$ & $-0,035$ & $-0,078$ & 0,055 & 0,080 & 0,263 & 0,221 & 0,083 & $-0,281$ & $-0,050$ & $-0,151$ \\
\hline \multirow{2}{*}{$\begin{array}{l}\text { udder } \\
\text { attachment }\end{array}$} & front & $-0,095$ & $-0,095$ & 0,334 & 0,430 & 0,091 & $-0,059$ & 0,136 & 0,000 & 0,038 & 0,070 & 0,173 \\
\hline & rear & $-0,219$ & $-0,219$ & 0,187 & 0,030 & 0,201 & 0,104 & 0,192 & $-0,129$ & $-0,143$ & 0,129 & 0,139 \\
\hline \multicolumn{2}{|c|}{ central ligament } & 0,107 & 0,107 & $-0,004$ & $-0,266$ & $-0,028$ & $-0,155$ & 0,159 & $-0,020$ & 0,028 & 0,304 & 0,27 \\
\hline \multicolumn{2}{|c|}{ udder depth } & 0,158 & 0,158 & 0,053 & 0,310 & 0,014 & $-0,341$ & 0,134 & $-0,012$ & $-0,308$ & 0,288 & $-0,161$ \\
\hline \multirow{2}{*}{$\begin{array}{l}\text { teats } \\
\text { position }\end{array}$} & front & $-0,105$ & $-0,105$ & 0,070 & 0,135 & $-0,127$ & 0,110 & $-0,077$ & $-0,160$ & $-0,018$ & 0,057 & 0,019 \\
\hline & rear & $-0,091$ & $-0,091$ & $-0,109$ & $-0,039$ & $-0,171$ & 0,282 & $-0,043$ & 0,114 & 0,148 & 0,040 & $-0,030$ \\
\hline \multicolumn{2}{|l|}{ teats length } & $-0,434$ & $-0,434$ & $-0,067$ & 0,149 & 0,280 & 0,377 & 0,128 & 0,105 & $-0,131$ & 0,265 & $-0,109$ \\
\hline \multicolumn{2}{|c|}{ locomotion } & $-0,118$ & $-0,118$ & 0,065 & 0,455 & 0,131 & $-0,124$ & 0,258 & 0,158 & $-0,065$ & 0,082 & 0,017 \\
\hline \multicolumn{2}{|c|}{ body condition score } & 0,045 & 0,045 & $-0,140$ & 0,208 & 0,044 & $-0,046$ & 0,053 & 0,031 & 0,085 & 0,292 & $-0,020$ \\
\hline
\end{tabular}

Table3

Coefficients of phenotypic consolidation $\left(\mathrm{K}_{2}\right)$ of bull-sires daughters by descriptive traits of the conformation

\begin{tabular}{|c|c|c|c|c|c|c|c|c|c|c|c|c|}
\hline \multicolumn{2}{|c|}{$\begin{array}{l}\text { Descriptive trait of the } \\
\text { conformation: }\end{array}$} & $\begin{array}{l}\text { Iceberg } \\
(30)\end{array}$ & $\begin{array}{l}\text { V. Delight } \\
(n=37)\end{array}$ & $\begin{array}{l}\text { D. Capris } \\
(n=41)\end{array}$ & $\begin{array}{l}\text { Laurer } \\
(\mathrm{n}=21)\end{array}$ & $\begin{array}{l}\text { Hayes } \\
(\mathrm{n}=22)\end{array}$ & $\begin{array}{l}\text { Lyubimyy } \\
(\mathrm{n}=30)\end{array}$ & $\begin{array}{l}\text { Toprate } \\
(\mathrm{n}=39)\end{array}$ & $\begin{array}{c}\text { Modnyy } \\
(\mathrm{n}=25)\end{array}$ & $\begin{array}{l}\text { Motuzok } \\
(\mathrm{n}=21)\end{array}$ & $\begin{array}{l}\text { Milliam } \\
(n=28)\end{array}$ & $\begin{array}{c}\text { Front } \\
(\mathrm{n}=30)\end{array}$ \\
\hline \multicolumn{2}{|c|}{ height at sacrum } & $-0,078$ & $-0,051$ & 0,181 & 0,085 & 0,121 & 0,084 & 0,181 & $-0,181$ & 0,115 & 0,093 & 0,248 \\
\hline \multicolumn{2}{|c|}{ chest width } & $-0,037$ & 0,158 & $-0,270$ & 0,464 & 0,125 & 0,013 & $-0,077$ & $-0,047$ & 0,334 & 0,301 & $-0,378$ \\
\hline \multicolumn{2}{|l|}{ body depth } & $-0,211$ & 0,077 & 0,319 & 0,117 & 0,042 & $-0,284$ & 0,341 & 0,256 & $-0,154$ & 0,299 & $-0,056$ \\
\hline \multicolumn{2}{|l|}{ angularity } & $-0,270$ & 0,321 & 0,503 & 0,453 & $-0,158$ & 0,237 & 0,466 & 0,195 & $-0,079$ & 0,546 & $-0,295$ \\
\hline \multicolumn{2}{|l|}{ rump angle } & $-0,414$ & $-0,178$ & $-0,048$ & 0,261 & 0,316 & $-0,206$ & 0,301 & $-0,003$ & 0,003 & 0,521 & $-0,186$ \\
\hline \multicolumn{2}{|c|}{ rear width } & $-0,069$ & 0,192 & 0,281 & 0,283 & 0,133 & $-0,160$ & 0,236 & $-0,254$ & $-0,294$ & 0,285 & 0,160 \\
\hline \multicolumn{2}{|c|}{ angle of pelvic limbs } & $-0,256$ & $-0,030$ & 0,141 & 0,344 & 0,084 & 0,398 & 0,015 & $-0,460$ & $-0,344$ & 0,361 & $-0,268$ \\
\hline \multicolumn{2}{|c|}{ pelvic limbs posture } & $-0,312$ & 0,406 & 0,188 & 0,256 & 0,262 & $-0,188$ & 0,240 & 0,088 & $-0,172$ & 0,016 & $-0,164$ \\
\hline \multicolumn{2}{|c|}{ hoof angle } & $-0,167$ & 0,094 & $-0,036$ & 0,049 & 0,147 & 0,240 & 0,261 & $-0,012$ & $-0,363$ & 0,017 & $-0,122$ \\
\hline \multirow{2}{*}{$\begin{array}{l}\text { udder } \\
\text { attachment }\end{array}$} & front & $-0,280$ & 0,264 & 0,369 & 0,421 & 0,191 & $-0,198$ & 0,164 & $-0,056$ & 0,058 & 0,210 & 0,086 \\
\hline & rear & $-0,401$ & 0,137 & 0,238 & 0,080 & 0,305 & $-0,113$ & 0,261 & $-0,160$ & $-0,128$ & 0,246 & 0,089 \\
\hline \multicolumn{2}{|c|}{ central ligament } & $-0,056$ & 0,342 & 0,037 & $-0,218$ & 0,104 & $-0,433$ & 0,235 & $-0,093$ & $-0,134$ & 0,396 & 0,224 \\
\hline \multicolumn{2}{|c|}{ udder depth } & 0,206 & 0,412 & 0,104 & 0,337 & 0,047 & $-0,571$ & 0,218 & $-0,099$ & $-0,404$ & 0,329 & $-0,301$ \\
\hline \multirow{2}{*}{$\begin{array}{l}\text { teats } \\
\text { position }\end{array}$} & front & $-0,097$ & 0,314 & 0,038 & 0,142 & $-0,198$ & 0,127 & $-0,185$ & 0,089 & 0,007 & $-0,081$ & 0,090 \\
\hline & rear & $-0,061$ & 0,141 & $-0,074$ & 0,027 & $-0,206$ & 0,215 & $-0,043$ & 0,192 & 0,188 & $-0,021$ & $-0,070$ \\
\hline \multicolumn{2}{|l|}{ teats length } & $-0,207$ & 0,204 & $-0,108$ & 0,139 & 0,259 & 0,321 & 0,135 & 0,098 & $-0,124$ & 0,254 & 0,036 \\
\hline \multicolumn{2}{|c|}{ locomotion } & $-0,269$ & 0,057 & 0,134 & 0,475 & 0,219 & $-0,374$ & 0,306 & 0,120 & $-0,207$ & 0,240 & $-0,037$ \\
\hline \multicolumn{2}{|c|}{ body condition score } & 0,122 & $-0,175$ & 0,239 & 0,196 & $-0,042$ & 0,075 & 0,014 & 0,083 & 0,126 & 0,271 & 0,044 \\
\hline
\end{tabular}

Conclusions. The presence of a genetic influence of bull-sires on the degree of phenotypic consolidation of the majority of linear traits of daughters with a significant advantage of Holstein producers was established. 


\section{References:}

1. Basovs'kyi, M. Z., Rudyk, I. A. and Burkat, V. P., 1992. Vyroshchuvannya, otsinka i vykorystannya plidnykiv [Growth, estimation and use of sires]. K.: Urozhay.

2. Boyko, Yu. M. 2011. Fenotypova konsolidatsiya liniy ukrayins'koyi buroyi molochnoyi porody za oznakamy dovichnoho vykorystannya [Phenotypic consolidation of lines of Ukrainian Brown dairy breed by traits of longevity use]. Visnyk Sums'koho NAU. Seriya: "Tvarynnytstvo". Sumy, no. 7(18), pp. 101-103.

3. Ivanov, I. A. and Malenivs'ka, S. P., 2012. Prohnozuvannya dovichnoyi molochnoyi produktyvnosti koriv ukrayins'koyi chorno-ryaboyi molochnoyi porody [Prediction of lifetime milk productivity of cows of Ukrainian Black-and-White dairy breed]. Suchasni problemy selektsiyi, rozvedennya ta hihiyeny tvaryn : zb. nauk. prats' Vinnyts'koho NAU. Vinnytsya, no. 5(67), pp. 111114.

4. Kohut, M. I. 2014. Otsinka buhayiv-plidnykiv za typom budovy tila yikh dochok [Estimation of sires by body type of their daughters]. Peredhirne ta hirs'ke zemlerobstvo i tvarynnytstvo. L'viv, no. 56(2), pp. 144-149.

5. Merkur'eva, E. K. 1977. Geneticheskie osnovy selektsii v skotovodstve [Genetic Principles of the selection in livestock]. M.: Kolos.

6. Khmel'nychyi, L. M., Ladyka, V. I. Polupan, Yu. P. and Salohub, A. M., 2008. Metodyka liniynoyi klasyfikatsiyi koriv molochnykh i molochno-m'yasnykh porid za typom [The method of linear classification cows of dairy and dairy-beef breeds by type]. Sumy: "Mriya-1", 28.

7. Pelekhatyy, M. S. and Kochuk-Yashchenko, O. A., 2014. Vplyv henotypu koriv-pervistok ukrayins'koyi chorno-ryaboyi molochnoyi porody na yikh ekster"yernyy typ, molochnu produktyvnist' i vidtvornu zdatnist' [The genotype influence of cows firstcalf Ukrainian Black-and-White dairy breed on their conformation type, milk production and reproductive ability]. Nauk. visn. L'vivs'koho nats. un-tu vet. medytsyny ta biotekhnolohiy im. S. Z. Hzhyts'koho, no. 16(3), pp. 143-158.

8. Polupan, Yu. P. 2000. Otsinka buhayiv za typom dochok [Estimation of sires according to the type of daughters]. Visnyk ahrarnoyi nauky, no. 5, pp. 45-49.

9. Polupan, Yu. P. 2005. Metody vyznachennya stupenya fenotypnoyi konsolidatsiyi selektsiynykh hrup tvaryn [Methods for determining the degree of phenotypic consolidation of animals breeding group]. Metodyky naukovykh doslidzhen' zi selektsiyi, henetyky i biotekhnolohiyi u tvarynnytstvi. K.: Ahrarna nauka, pp. 52-61.

10. Polupan, Yu. P. 1996. Otsenka stepeni fenotipicheskoy konsolidatsii genealogicheskikh grupp zhivotnykh [Assessment of the degree of phenotypic consolidation genealogical groups of animals]. Zootekhniya, no. 10, pp. 13-15.

11. Ladyka, V. I., Khmel'nychyi, L. M., Burkat, V. P. and Ruban, S. Yu., 2010. Reyestratsiya ICAR. Dovidnyk [Registration ICAR. Reference book]. Sumy: Sums'kyy Natsional'nyy Ahrarnyy Universytet. 457.

12. Stolyar, Zh. V., 2014. Fenotypova konsolidatsiya hrup koriv riznykh typiv konstytutsiyi [Phenotypic consolidate of cows groups of different types of constitution]. Rozvedennya i henetyka tvaryn: mizhvid. temat. nauk. zb. K.: Ahrarna nauka, no. 48, pp. 129-136.

13. Khmel'nychyy, L. M., 2007. Otsinka ekster"yeru tvaryn v systemi selektsiyi molochnoyi khudoby : monohrafiya [Estimation of animals conformation in the breeding system of dairy cattle : monograph]. Sumy: "Mriya-1".

14. Khmel'nychyy, L. M., 2006. Fenotypova konsolidatsiya selektsiynykh hrup tvaryn ukrayins'koyi chervono-ryaboyi molochnoyi porody za ekster"yernym typom [Phenotypic consolidation of breeding groups of animals of Ukrainian Red-andWhite dairy breed by conformation type]. Visnyk Cherkas'koho instytutu APV. Cherkasy, no. 6, pp. 101-115.

15. Khmel'nychyy, S. L., 2017. Estimation of the conformation of animals of Sumy intrabreed type of Ukrainian Blackand-White dairy breed. Ph.D. Thesis. Institute of Animal Breeding and Genetics NAAS.

\section{Список використаної літератури:}

1. Басовський, М. 3., Рудик І. А., Буркат В. П. Вирощування, оцінка і використання плідників. К. : Урожай, 1992. 216

c.

2. Бойко, Ю.М. Фенотипова консолідація ліній української бурої молочної породи за ознаками довічного використання. Вісник Сумського НАУ. Серія: "Тваринниитво”. Суми, 2011. Вип. 7(18). С. 101-103.

3. Іванов, І. А., Маленівська С. П. Прогнозування довічної молочної продуктивності корів української чорно-рябої молочної породи. Сучасні проблеми селекції, розведення та гігієни тварин : зб. наук. праць Вінницького НАУ. Вінниця, 2012. Вип. 5(67). С. 111-114.

4. Когут, М. І. Оцінка бугаїв-плідників за типом будови тіла їх дочок. Передгірне та гірське землеробство і твариннищтво. Львів, 2014. Вип. 56(2). С. 144-149.

5. Меркурьева Е. К. Генетические основы селекции в скотоводстве. М.: Колос, 1977. 240 с.

6. Методика лінійної класифікації корів молочних і молочно-м'ясних порід за типом / Л. М. Хмельничий, В. І. Ладика, Ю. П. Полупан, А. М. Салогуб. Суми: ВВП "Мрія-1" ТОВ. - 2008, 12 с.

7. Пелехатий М. С., Кочук-Ященко О. А. Вплив генотипу корів-первісток української чорно-рябої молочної породи на їх екстер'єрний тип, молочну продуктивність і відтворну здатність. Наук. вісник ЛНУВМ ім. С. З. Гжицького. Львів, 2014. Т. 16, № 3, ч. 3. С. 143-158.

8. Полупан Ю. П. Оцінка бугаїв за типом дочок. Вісник аграрної науки. 2000. Вип. 5. С. 45-49.

9. Полупан Ю. П. Методи визначенння ступеня фенотипної консолідації селекційних груп тварин. Методики наукових досліджень зі селекції, генетики і біотехнології у тваринництві. К. : Аграрна наука, 2005. С. 52-61.

10. Полупан, Ю. П. Оценка степени фенотипической консолидации генеалогических групп животных. Зоотехния. 1996. Вып. 10. С. 13-15. 
11. Реєстрація ICAR : довідник. В. І. Ладика, Л. М. Хмельничий, В. П. Буркат, С. Ю. Рубан. Суми : СНАУ, 2010. 457 c.

12. Столяр, Ж. В. Фенотипова консолідація груп корів різних типів конституції. Розведення і генетика тварин. К. : Аграрна наука, 2014. Вип. 48. С. 129-136.

13. Хмельничий, Л. М. Оцінка екстер'єру тварин в системі селекції молочної худоби : монографія.Суми : Мрія, 2007. $260 \mathrm{C}$.

14. Хмельничий, Л. М. Фенотипова консолідація селекційних груп тварин української червоно-рябої молочної породи за екстер'єрним типом. Вісник Черкаського інституту АПВ. Черкаси, 2006. Вип. 6. С. 101-115.

15. Хмельничий, С. Л. Оцінка екстер'єру тварин сумського внутрішньопородного типу української чорно-рябої молочної породи: дис. ... кандидата с.-г. наук : 06.02.01 / С. Л. Хмельничий; Ін-т розведення і генетики тварин НААН. с. Чубинське Київської обл., 2017. 222 с.

Хмельничий Л. М., доктор сільськогосподарських наук, професор

Хмельничий С. Л., кандидат сільськогосподарських наук,

Бардаш Д. О., магистрант

Сумський національний аграрний університет

Фенотипова консолідованість дочок бугаїв-плідників оцінених за методикою лінійної класифікації

Метою наших досліджень було визначення ступеня коефріцієнтів фенотипової консолідованості дочок бугаївплідників у сумському внутрішньопородному типі української чорно-рябої молочної породи, оцінених за лінійними ознаками, які характеризують екстер'єрний тип тварин. Експериментальною базою досліджень була інфрормація з лінійної класиффікації корів-первісток сумського внутрішньопородного типу української чорно-рябої молочної породи племінного заводу ПП "Буринське" Підліснівського відділення Сумського району. Оцінка корів-первісток за типом проводилася за використання методики лінійної класифікації за двома системами - 9-бальною, з лінійним описуванням 18 статей екстер'єру і 100-бальною - з урахуванням чотирьох комплексів селекційних ознак, які характеризують: молочний тип, тулуб, кінцівки та вим'я. Коефріцієнти фенотипової консолідованості (К і К К селекційних груп тварин за лінійними ознаками екстер'єру визначали за фрормулами, запропонованими Ю. П. Полупаном (2005). Рівень фенотипової консолідованості дочок бугаїв-плідників, оцінених за груповими ознаками екстер'єру, засвідчив, що незалежно від походження коефріцієнти френотипової консолідованості за загальною оцінкою типу мають додатне значення з широкою мінливістю за коефріцієнтом К ві о 0,056 до 0,512 та за коефріцієнтом К - від 0,065 до 0,505. Серед усіх оцінених за фенотиповою консолідованістю бугаїв найменш консолідованими за груповими лінійними ознаками виявились плідники української чорно-рябої молочної породи - Мотузок та Фронт. Серед бугаїв голштинської породи кращі за груповими ознаками та загальною оцінкою типу - В. Ділайт (К $\left.\kappa_{1}=0,242-0,347 ; K_{2}=0,247-0,349\right)$, Д. Капріс $\left(K_{1}=0,085-0,341 ; K_{2}=0,089-0,348\right)$ ma Хайєс $\left(K_{1}=0,071-0,375 ; K_{2}=0,082-0,370\right)$. Із бугаїв української чорно-рябої молочної породи кращим виявився Айсбере (K $\left.K_{1}=0,059-0,478 ; K_{2}=0,047-0,472\right)$. Величина ступеня фенотипової консолідованості описових ознак лінійної оцінки дочок бугаїв, незалежно від походження, відрізняється значно вищою мінливістю у порівнянні з груповими ознаками. Коефіцієнти феннтипової консолідованості, вирахувані за фрормулою К, варіюють за даними оцінки усіх бугаїв-плідників - від -0,434 (довжина дійок дочок Айсберга), до 0,504 (нахил заду дочок Мілліама). Ще вища мінливість коефіцієнтів фенотипової консолідованості виявлена за формулою К, рівень яких змінюється від -0,571 (глибина вимені дочок Любимого), до 0,546 (кутастість дочок Мілліама). За коефіцієнтами френотипової консолідованості описових ознак К $_{1}$ К ${ }_{2}$ не виявилося ні одного плідника лише з додатними значеннями. Найбільш консолідованими за переважною більшістю описових ознак виявилися бугаї-плідники голштинської породи - Лауер, Топрейт та Мілліам. Найвищу консолідованість серед описових ознак мали дочки усіх бугаїв за кутастістю 3 найбільшою кількістю додатних значень коефіцієнтів. Встановлена наявність генетичного впливу бугаїв-плідників на ступінь фенотипової консолідованості більшості лінійних ознак їхніх дочок з істотною перевагою голштинських плідників.

Ключові слова: українська чорно-ряба молочна порода, екстер'єрний тип, френотипова консолідованість, бугаї-плідники.

Дата надходження до редакції: 12.12.2019 р. 